\section{OPEN ACCESS}

Approved by:

Frontiers Editorial Office,

Frontiers Media SA, Switzerland

*Correspondence:

Daniela Bulgarell daniela.bulgarelli@unito.it

Specialty section:

This article was submitted to

Developmental Psychology,

a section of the journal

Frontiers in Psychology

Received: 10 September 2021 Accepted: 23 September 2021

Published: 19 October 2021

Citation:

Caputi M, Dulay KM, Bulgarelli D,

Houston-Price $C$, Cerrato $G$

Fanelli $M$, Masento NA and Molina $P$

(2021) Corrigendum: See \& Eat! Using E-books to Promote Vegetable Eating

Among Preschoolers: Findings From an Italian Sample.

Front. Psychol. 12:773658

doi: 10.3389/fpsyg.2021.773658

\title{
Corrigendum: See \& Eat! Using E-books to Promote Vegetable Eating Among Preschoolers: Findings From an Italian Sample
}

\section{Marcella Caputi ${ }^{1,2}$, Katrina May Dulay ${ }^{3,4}$, Daniela Bulgarelli ${ }^{1 *}$, Carmel Houston-Price ${ }^{3}$ Giuseppina Cerrato ${ }^{5}$, Mauro Fanelli ${ }^{5}$, Natalie A. Masento ${ }^{3}$ and Paola Molina ${ }^{1,6}$}

${ }^{1}$ Department of Psychology, Università degli Studi di Torino, Torino, Italy, ${ }^{2}$ Sigmund Freud University, Milano, Italy, ${ }^{3}$ School of Psychology and Clinical Language Sciences, University of Reading, Reading, United Kingdom, ${ }^{4}$ Department of Education, University of Oxford, Oxford, United Kingdom, ${ }^{5}$ Department of Chemistry, Università degli Studi di Torino, Torino, Italy,

${ }^{6}$ Interuniversity Department of Regional and Urban Studies and Planning. Università degli Studi di Torino, Torino, Italy

Keywords: vegetable intake, visual familiarity, visual exposure, healthy eating, food fussiness, mealtime goal

\section{A Corrigendum on}

See \& Eat! Using E-books to Promote Vegetable Eating Among Preschoolers: Findings From an Italian Sample

by Caputi, M., Dulay, K. M., Bulgarelli, D., Houston-Price, C., Cerrato, G., Fanelli, M., Masento, N. A., and Molina, P. (2021). Front. Psychol. 12:712416. doi: 10.3389/fpsyg.2021.712416

In the published article, there was an error in the affiliation superscript of Daniela Bulgarelli. Instead of " $2 *$ ", it should be " 1 *”.

The authors apologize for this error and state that this does not change the scientific conclusions of the article in any way. The original article has been updated.

Publisher's Note: All claims expressed in this article are solely those of the authors and do not necessarily represent those of their affiliated organizations, or those of the publisher, the editors and the reviewers. Any product that may be evaluated in this article, or claim that may be made by its manufacturer, is not guaranteed or endorsed by the publisher.

Copyright (c) 2021 Caputi, Dulay, Bulgarelli, Houston-Price, Cerrato, Fanelli, Masento and Molina. This is an open-access article distributed under the terms of the Creative Commons Attribution License (CC BY). The use, distribution or reproduction in other forums is permitted, provided the original author(s) and the copyright owner(s) are credited and that the original publication in this journal is cited, in accordance with accepted academic practice. No use, distribution or reproduction is permitted which does not comply with these terms. 